\title{
Forgone healthcare and financial burden due to out-of-pocket payments in Bangladesh: a multilevel analysis
}

Md. Mizanur Rahman ${ }^{1 *}$ (D) Md. Rashedul Islam², Md. Shafiur Rahman³, Fahima Hossain ${ }^{4}$, Ashraful Alam²,

Md. Obaidur Rahman ${ }^{5}$, Jenny Jung ${ }^{4}$ and Shamima Akter ${ }^{1}$

\begin{abstract}
Background: Ensuring access to health services for all is the main goal of universal health coverage (UHC) plan. Out-of-pocket (OOP) payment still remains the main source of funding for healthcare in Bangladesh. The association between barriers to accessing healthcare and over-reliance on OOP payments has not been explored in Bangladesh using nationally representative household survey data. This study is a novel attempt to examine the burden of OOP payment and forgone healthcare in Bangladesh, and further explores the inequalities in catastrophic health expenditures (CHE) and forgone healthcare at the national and sub-national levels.

Methods: This study used data from the most recent nationally representative cross-sectional survey, Bangladesh Household Income and Expenditure Survey, conducted in 2016-17 ( $N=39,124)$. In order to identify potential determinants of $\mathrm{CHE}$ and forgone healthcare, multilevel Poisson regression was used. Inequalities in $\mathrm{CHE}$ and forgone healthcare were measured using the slope index of inequality.

Results: Around $25 \%$ of individuals incurred CHE and $14 \%$ of the population had forgone healthcare for any reasons. The most common reasons for forgone healthcare were treatment cost (17\%), followed by none to accompany or need for permission (5\%), and distance to health facility (3\%). Multilevel analysis indicated that financial burden and forgone care was higher among households with older populations or chronic illness, and those who utilize either public or private health facilities. Household consumption quintile had a linear negative association with forgone care and positive association with CHE.
\end{abstract}

Conclusion: This study calls for incorporation of social safety net in health financing system, increase health facility, and gives priority to the disadvantaged population to ensure access to health services for all.

Keywords: Out-of-pocket health payment, Catastrophic health expenditure, Forgone healthcare, Multilevel analysis, Bangladesh

\footnotetext{
*Correspondence: mizanurrub78@gmail.com; mizanur.rahman@r.hit-u.ac.jp ${ }^{1}$ Hitotsubashi Institute for Advanced Study, Hitotsubashi University, 2-1 Naka Kunitachi, Tokyo 186-8601, Japan

Full list of author information is available at the end of the article
}

(c) The Author(s). 2022 Open Access This article is licensed under a Creative Commons Attribution 4.0 International License, which permits use, sharing, adaptation, distribution and reproduction in any medium or format, as long as you give appropriate credit to the original author(s) and the source, provide a link to the Creative Commons licence, and indicate if changes were made. The images or other third party material in this article are included in the article's Creative Commons licence, unless indicated otherwise in a credit line to the material. If material is not included in the article's Creative Commons licence and your intended use is not permitted by statutory regulation or exceeds the permitted use, you will need to obtain permission directly from the copyright holder. To view a copy of this licence, visit http://creativecommons.org/licenses/by/4.0/ The Creative Commons Public Domain Dedication waiver (http://creativecommons.org/publicdomain/zero/1.0/) applies to the data made available in this article, unless otherwise stated in a credit line to the data. 


\section{Background}

Ensuring access to quality health services for all and protecting population from financial hardship when they receive services is the key health-related target of the Sustainable Development Goals (SDGs) that all member states of the United Nations have agreed to achieve by 2030 [1, 2]. However, in 2015, approximately 808 million people globally experienced catastrophic health expenditure (CHE) [3], and more than 97 million people were pushed below the poverty line due to out-of-pocket (OOP) payment for health care [4]. Overreliance on OOP payments, poor functioning of health insurance plans, and different socio-demographic and cultural factors were found to hinder people's access to health care in times of need [5-9]. Identifying dimensions of barriers to access to health care is therefore crucial for helping policy makers to address the target population and ensure access for all citizens.

In low- and middle-income countries (LMICs), substantial improvements in access to health services have been achieved in the last few decades. However, the inequalities in the healthcare of LMICs persistently deprive their most disadvantaged and socially excluded populations of the benefits of access to health service and desirable health outcomes. To achieve access and quality of care for all populations, Tanahashi [8], Levesque [9], and other experts $[5,10]$ developed a remarkable health coverage framework based on three dimensions: availability, accessibility, and acceptability. Availability mainly includes human power, facilities, and drugs; accessibility considers distance, and cost related to user fee and transportation; and acceptability includes wide range of socio-demographic, and other demand side characteristics. These three dimensions are mainly responsible for directing the coverage, access, quality, delayed or forgone health care in any countries [5, 8-10].

Like many LMICs, the health financing system in Bangladesh is underfunded, lacking of proper health insurance, and heavily relies on OOP payment [11]. The OOP constitutes $67 \%$ of the total health expenditure in Bangladesh [12], and wide pro-rich inequalities with low coverage is observed in most of the health interventions $[13,14]$. As a result of higher dependency on OOP payments, around 16\% households incurred financial catastrophe in 2011, 5\% non-poor households became poor, and 7\% of Bangladeshi households experienced distress financing such as borrow money, loan or sell assets to cope up with unpredictable OOP payment [13, 14]. Although, studies on the levels and determinants of financial hardship are not new in Bangladesh [13], little is known to identify populations at high risk of foregoing healthcare in context of Tanahashi barrier dimension such as availability, accessibility and acceptability reasons [8]. To address these questions, we used most recent nationally representative household level survey data to (a) explore the burden of OOP payments for healthcare, and (b) to estimate prevalence and determinants of foregone health care due to availability, accessibility and acceptability reasons using multilevel modeling.

\section{Methods}

\section{Data sources}

Household Income and Expenditure Survey (HIES) conducted during 2016-17 in Bangladesh was used in this study. The HIES is a two-stage stratified sample design and the survey covered eight administrative regions of the country namely Barisal, Chittagong, Dhaka, Khulna, Mymensingh, Rajshahi, Rangpur, and Sylhet. In the first stage of sampling, 2304 primary sampling units (PSU) were selected from the list of the 2011 Housing and Population Census enumerations area (CEA). In the second stage, a fixed number of 20 households were selected from each of the selected PSU making the final sample size to be 46,080 households. In our study, we included participants if they reported any illness or injuries in the 12 months or 30 days recall periods. Based on this criteria, 39,124 household members were included in this study for analysis. The key characteristic of this survey included an integrated household questionnaire which covered household roster, food consumption expenditure, non-food expenditure, housing, assets, education, durable goods, health, individual level care-seeking behavior, individual level healthcare costs, and sources of financing for healthcare.

\section{Burden of OOP payment variables}

OOP payment was defined as the total amount of money paid by the household while receiving the health care services. These included consultation fees, diagnostic fees, hospital bills, transportation, and expenditure on medications. The variable "financial catastrophe" was defined as the percentage of individual OOP expenses on household consumption expenditure, non-food expenditure, or household capacity to pay in the past year. The determination of the thresholds in analyzing catastrophic expenditure varies. The most common thresholds are either $10 \%$ or $15 \%$ of total household consumption expenditure [15-17], $25 \%$ or $40 \%$ for non-food expenditure $[6,16,18]$, or $40 \%$ household capacity to pay [19]. To compare the findings of other studies, the incidence of CHE was presented based on $40 \%$ threshold of non-food expenditure.

\section{Foregone healthcare determinants}

In the HIES, every individual member was asked whether he/she sought any type of medical treatment for their health problems in the last 12 months ("yes"/"no")? Respondents, who replied "no", were then asked the 
main reason for not seeking medical care. Possible answers were: 1) problem was not serious; 2) treatment cost is too much; 3) distance is too long; 4) afraid of discovering serious illness; 5) there was none to accompany; 6) decision maker does not think I should go; 7) don't know where to go; 8) others reasons. To assess the forgone care due to expense, we constructed binary ("yes"/ "no") variables and determined whether or not the participants avoided healthcare for its expensive costs.

\section{Predictor variables}

Predictor variables were selected by following Andersen's Behavior model and other literatures [7, 20-22]. The framework suggests that healthcare utilization is influenced by three main factors: predisposing, enabling, and need. The predisposing component - demographic, social structure, and attitude and beliefs about medical care - are factors that are commonly associated with how an individual will utilize health care services prior to the onset of disease or illness. The enabling component is the financial capacity and resource availability. The need component is based on the immediate reason for why the patient sought health care. Because this study did not evaluate utilization of health services, predictor variables related to the predisposing and enabling factors were included in the analysis. Furthermore, we followed previous studies conducted in LMICs for the selection and categorization of predictor variables. Evidence suggested that disadvantaged households [23-27]. household age structure $(\leq 5$ year children, $\geq 60$ years elderly) [25-28], urban location [25], female household head [28], presence of chronic illness [25-30] and increased illness episodes in children $[25,28]$ were positively associated with CHE and forgone healthcare. However, households with educated household head were less likely to have CHE and forgone healthcare [25-27, 29]. Administratively, Bangladesh is divided into eight regions- Barisal, Chittagong, Dhaka (Capital), Khulna, Mymensing, Rajshai, Rangpur, and Shylhet. These administrative regions are not homogenously developed. For example, the Rangpur is deprived than other regions. From a policy perspective, evidence of the regional distribution of $\mathrm{CHE}$ and forgone healthcare could be of importance to Bangladesh. In this study, we were interested to see the variation of $\mathrm{CHE}$ and forgone healthcare by household demography, illness and injury, regional and geographical location, and economic condition such as age of population $(0-4,5-9,10-14,15-19$, 20-24, 25-64, $\geq 65$ years), gender (male, female), religion (Muslim, Non-Muslim), marital status (never married, currently married, widowed/divorced/ separated), presence of chronic illness (yes, no), income earner (yes, no), inpatient care (none, public hospital, private hospital/clinics), outpatient care (none, public providers, private providers, selfmedication/pharmacy/traditional healer), household consumption quintile (poorest, poorer, average, richer, richest), and place of residence (rural, urban).

\section{Statistical analysis}

Mean and percentage with 95\% confidence interval were used to present study characteristics, CHE, and forgone healthcare at the national and regional level. OOP health expenditure was characterized by excess zeroes corresponding to individuals who reported no health expenditure in the past 12 months. OOP health expenditure also relied on participation in seeking care. Since ordinary regression models are inappropriate to control for two stochastic approaches (participation and level of expenses), we therefore preferred the Heckman selection model over standard linear regression $[2,31]$. The Heckman model includes a two-stage procedure: a selection equation including the probability of attending a health service in the first stage and a prediction equation for the model's outcome variable-level of OOP health expenditure at the second stage. In our study, Heckman selection model was further used to identify the determinants of OOP health payments on medical treatment, conditional upon having sought care from any healthcare provider (yes/no). In the case of rare events, Poisson regression can provide more valid estimates than logistic regression [32, 33]. Because barrier to access healthcare resulting from high OOP payments can be a rare event, in our study three-level Poisson regression models with random intercept at the households and community levels were used to investigate the association between individual-, household-, and community-level characteristics and the selected outcome variables, especially $\mathrm{CHE}$ and forgone healthcare. Adjusted relative risk (RR) with their 95\% confidence interval (CI) were reported from multilevel Poisson regression model.

The inequalities in CHE and forgone healthcare were measured using regression-based slope index of inequality (SII). The values of SII were expressed in percentage points. Positive value of SII indicates that the rich households have lower forgone healthcare or incur lower financial catastrophe than the poor households. Conversely, the negative value indicates that the poor households have higher forgone healthcare or incur higher financial catastrophe than the rich households. An SII value of zero indicates no inequality. Data management and statistical analysis was conducted using Stata/SE version 16.1 (StataCorp LP, College Station, TX) and R version 4.2.1. 


\section{Results}

\section{Respondents' characteristics}

The characteristics of the study population are shown in Table 1 . Of the 39,124 household members, more than half were females (54\%), mean age of participants was around 28 years, and average household size was around 5 members. In the study population, $29 \%$ suffered from chronic illness, $4 \%$ used inpatient care, and $86 \%$ used outpatient care. Among outpatient care users, 12\% used public health services, $41 \%$ used private health services, and $32 \%$ used self-medication/pharmacy/traditional healer. Around two-thirds of the study sample lived in rural areas. On average, total annual OOP health expenditure was BD TK 12362.2 (95\% CI, 11724.5-12,999.8).

\section{Determinants of burden of healthcare expenditure}

The determinants of CHE results is presented in Table 2. Overall, around $25 \%$ of population incurred

Table 1 Respondent characteristics

\begin{tabular}{|c|c|c|c|c|}
\hline \multirow[t]{2}{*}{ Variables } & \multirow[t]{2}{*}{ Frequency } & \multirow[t]{2}{*}{ Values } & \multicolumn{2}{|c|}{ 95\% confidence interval } \\
\hline & & & Lower & Upper \\
\hline \multicolumn{5}{|l|}{ Mean $(95 \% \mathrm{Cl})$} \\
\hline Household size & 39,124 & 4.51 & 4.45 & 4.56 \\
\hline Age, years & 39,124 & 27.53 & 27.12 & 27.93 \\
\hline OOP payments (BD TK) & 39,124 & $12,362.17$ & $11,724.55$ & $12,999.78$ \\
\hline \multicolumn{5}{|l|}{ Percentage $(95 \% \mathrm{Cl})$} \\
\hline \multicolumn{5}{|l|}{ Gender } \\
\hline Female & 21,248 & 54.36 & 53.69 & 55.04 \\
\hline Male & 17,875 & 45.64 & 44.96 & 46.31 \\
\hline \multicolumn{5}{|l|}{ Religion } \\
\hline Muslim & 34,758 & 90.10 & 88.29 & 91.65 \\
\hline Non-Muslim & 4363 & 9.90 & 8.35 & 11.71 \\
\hline \multicolumn{5}{|l|}{ Marital status } \\
\hline Never married & 10,934 & 34.27 & 33.26 & 35.30 \\
\hline Currently married & 19,930 & 58.88 & 57.86 & 59.88 \\
\hline Widowed $^{\mathrm{a}}$ & 2277 & 6.85 & 6.46 & 7.27 \\
\hline \multicolumn{5}{|l|}{ Have chronic illness } \\
\hline Yes & 12,004 & 29.00 & 27.85 & 30.18 \\
\hline No & 27,120 & 71.00 & 69.82 & 72.15 \\
\hline \multicolumn{5}{|l|}{ Inpatient care } \\
\hline None & 37,312 & 95.56 & 95.06 & 96.01 \\
\hline Public hospital/clinic & 1099 & 2.58 & 2.27 & 2.94 \\
\hline Private providers & 713 & 1.86 & 1.63 & 2.12 \\
\hline \multicolumn{5}{|l|}{ Outpatient care } \\
\hline None & 4631 & 14.08 & 12.30 & 16.08 \\
\hline Public hospital/clinic & 5214 & 12.47 & 11.67 & 13.31 \\
\hline Private hospital/clinic & 16,396 & 41.34 & 39.39 & 43.33 \\
\hline Self-medication ${ }^{\mathrm{b}}$ & 12,883 & 32.11 & 30.63 & 33.62 \\
\hline \multicolumn{5}{|l|}{ Income earner } \\
\hline No & 25,490 & 72.37 & 71.57 & 73.16 \\
\hline Yes & 9940 & 27.63 & 26.84 & 28.43 \\
\hline \multicolumn{5}{|l|}{ Place of residence } \\
\hline rural & 27,712 & 74.10 & 71.54 & 76.51 \\
\hline urban & 11,412 & 25.90 & 23.49 & 28.46 \\
\hline
\end{tabular}

Widowed/Divorced/Separated

${ }^{b}$ Self-medication/traditional healer

BD TK Bangladesh currency Taka 
Table 2 Multilevel Poisson regression model of risk of catastrophic healthcare expenditure, Bangladesh, $2017(\mathrm{~N}=39,124)$

\begin{tabular}{|c|c|c|c|c|}
\hline Variable & Frequency of catastrophic expenditure & Proportion $(95 \% \mathrm{Cl})$ & RR $(95 \% \mathrm{Cl})$ & $p$-values \\
\hline \multicolumn{5}{|l|}{ Age, years } \\
\hline $0-4$ & 1297 & $19.7(17.7-21.9)$ & 1.00 & \\
\hline $5-9$ & 756 & $19.5(16.9-22.4)$ & $0.90(0.82-0.99)$ & 0.02 \\
\hline $10-14$ & 657 & $22.0(19.8-24.4)$ & $0.91(0.84-1.00)$ & 0.05 \\
\hline $15-19$ & 572 & $21.7(19.3-24.4)$ & $0.89(0.80-0.98)$ & 0.02 \\
\hline $20-24$ & 588 & $25.9(23.2-28.7)$ & $0.99(0.88-1.10)$ & 0.80 \\
\hline $25-64$ & 4742 & $27.1(25.8-28.4)$ & $0.89(0.79-1.00)$ & 0.05 \\
\hline$\geq 65$ & 944 & $34.3(31.6-37.1)$ & $1.05(0.92-1.19)$ & 0.47 \\
\hline \multicolumn{5}{|l|}{ Gender } \\
\hline Male & 4326 & $24.1(22.7-25.7)$ & 1.00 & \\
\hline Female & 5230 & $25.0(23.6-26.3)$ & $1.02(0.98-1.06)$ & 0.38 \\
\hline \multicolumn{5}{|l|}{ Religion } \\
\hline Muslim & 8657 & $24.9(23.6-26.4)$ & 1.00 & \\
\hline Non-Muslim & 899 & $21.3(18.3-24.7)$ & $0.91(0.82-1.00)$ & 0.06 \\
\hline \multicolumn{5}{|l|}{ Marital status } \\
\hline Never married & 2358 & $22.3(20.2-24.6)$ & 1.00 & \\
\hline Currently married & 5535 & $28.0(266-29.3)$ & $1.14(1.04-1.25)$ & $<0.01$ \\
\hline Widowed ${ }^{a}$ & 643 & $28.1(25.5-31.0)$ & $1.14(1.01-1.27)$ & 0.03 \\
\hline \multicolumn{5}{|l|}{ Has a chronic disease } \\
\hline No & 5627 & $21.2(19.8-22.6)$ & 1.00 & \\
\hline Yes & 3929 & $32.9(31.1-34.7)$ & $1.19(1.14-1.24)$ & $<0.01$ \\
\hline \multicolumn{5}{|l|}{ Outpatient care } \\
\hline None & 543 & $11.0(8.4-14.4)$ & 1.00 & \\
\hline Public hospital & 1872 & $37.7(34.6-40.9)$ & $2.59(2.21-3.04)$ & $<0.01$ \\
\hline Private hospital/clinic & 5210 & $32.8(31.1-34.5)$ & $2.37(2.03-2.77)$ & $<0.01$ \\
\hline Self-medication ${ }^{\text {b }}$ & 1931 & $14.9(13.4-16.5)$ & $1.32(1.13-1.55)$ & $<0.01$ \\
\hline \multicolumn{5}{|l|}{ Inpatient care } \\
\hline None & 8469 & $22.9(21.6-24.1)$ & 1.00 & \\
\hline Public hospital & 597 & $56.1(50.3-61.6)$ & $1.58(1.48-1.69)$ & $<0.01$ \\
\hline Private hospital/clinic & 490 & $69.5(63.4-75.0)$ & $1.78(1.60-2.00)$ & $<0.01$ \\
\hline \multicolumn{5}{|l|}{ Income earner } \\
\hline Yes & 2573 & $25.7(24.1-27.4)$ & 1.00 & \\
\hline No & 6349 & $25.4(24.0-26.9)$ & $1.02(0.97-1.07)$ & 0.49 \\
\hline \multicolumn{5}{|l|}{ Consumption quintile } \\
\hline Q1 (poorest) & 970 & $16.0(14.3-17.9)$ & 1.00 & \\
\hline Q2 & 1332 & $18.6(16.8-20.5)$ & $1.17(1.05-1.31)$ & 0.01 \\
\hline Q3 & 1681 & $20.5(18.6-22.4)$ & $1.35(1.21-1.50)$ & $<0.01$ \\
\hline Q4 & 2276 & $27.2(24.4-30.2)$ & $1.70(1.53-1.9)$ & $<0.01$ \\
\hline Q5 (richest) & 3297 & $32.8(29.9-35.8)$ & $2.11(1.90-2.34)$ & $<0.01$ \\
\hline Household size & - & - & $0.97(0.96-0.99)$ & $<0.01$ \\
\hline \multicolumn{5}{|l|}{ Place of residence } \\
\hline Rural & 7207 & $26.4(24.9-27.9)$ & 1.00 & \\
\hline Urban & 2349 & $19.4(17.1-22.0)$ & $0.71(0.66-0.77)$ & $<0.01$ \\
\hline Total & 9556 & $24.6(23.3-25.9)$ & & \\
\hline
\end{tabular}

$R R$ relative risk, $C l$ confidence interval

${ }^{a}$ Widowed/Divorced/Separated; ${ }^{b}$ Self-medication/pharmacy /traditional healer

$\mathrm{CHE}$ at $40 \%$ threshold of non-food consumption expenditure. The CHE for other definitions and thresholds such as $10 \%$ or $15 \%$ of total consumption, $25 \%$ of non-food, and $40 \%$ of household capacity to pay are presented in the supplemental appendix (Table S1). Almost similar incidence of CHE was found for total consumption and non-food consumption, but higher from household capacity to pay 
(Table S1). The highest incidence of CHE was found among individuals who utilized inpatient care (public hospital (56\%) and private hospital/clinic (70\%)), followed by individuals having chronic illness (33\%), aged 65 years or more (34\%), and belonging to wealthy socioeconomic condition (33\%). Multilevel analysis indicated that the risk of CHE was significantly high for participants who were widowed/separated, chronically ill, found to utilize public or private health services, and members of households in the richest quintile. Other determinants of $\mathrm{CHE}$ were household size and place of residence. Regarding the level of OOP payment, individuals reporting chronic illness, household size, inpatient and outpatient careseeking behavior, household consumption quintile, and place of residence significantly affected the level of individual OOP healthcare spending (supplemental appendix, Table S2).

\section{Prevalence and determinants of forgone healthcare}

Prevalence and determinants of forgone healthcare are presented in Fig. 1 and Table 3 respectively. Overall, $14 \%$ of the population (4613 out of 39,124 sample) had forgone healthcare for any reasons, including: problem was not serious (58\%), cost (17\%), none to accompany (5\%), distance (3\%), and afraid of discovering serious illness (3\%). For reasons related to cost of care, around 3\% population reported having forgone healthcare because it was unaffordable. Comparatively, a higher proportion of forgone healthcare was evident among elderly populations (4.4\%), widowed/divorced/separated (4.7\%), reported chronic illness (4.5\%), and in lower socioeconomic condition (4.5\%).

Multilevel regression model revealed that participants' age, gender, presence of chronic illness, and household consumption quintile were predicted to have significant impacts on foregone healthcare. However, predictors such as religion, marital status, income earner and place of residence were not found to be significant. Forgone healthcare was positively associated with participants' age and negatively with household consumption quintile. As compared to under five children, the risk of forgone healthcare was significantly higher among all age groups. The highest risk of forgone healthcare was found in populations aged 65 years or over (RR, 4.79; 95\% CI, 2.44 9.37) than under five children. The RR representing forgone healthcare among people with chronic illness was 1.73 times higher $(95 \% \mathrm{CI}, 1.45-2.07)$ than those without chronic condition. Participants those in the richest quintile had $82 \%$ (RR, 0.18 ; 95\% CI, 0.14-0.24) lower chance of forgone healthcare than those in the poorest quintile.

\section{Inequality in catastrophic payments and forgone healthcare}

Quintile-specific CHE and forgone healthcare by region is presented in Fig. 2. The higher wealth populations were correlated with a higher incidence of financial catastrophe observed at national and all regional levels. A wide disparity was observed both in CHE and forgone healthcare within and between regional levels. The overall incidence of CHE payment was the highest in Chittagong (31.4\%) and Barisal (30.6\%), and relatively low CHE was observed in Sylhet (16.3\%) and Dhaka (19.7\%) (Fig. 2A). Wealthier people faced lower financial catastrophe at national and all regional levels than the poorer populations (Fig. 2B). Greater pro-rich inequality in catastrophic payment was evident in Barisal (42.8 percentage points), Rajshahi (36.6 percentage points), and Chittagong (34.6 percentage points), whereas relatively lesser inequality was noticed in Dhaka (4.7 percentage points) and Sylhet (12.4 percentage points). In case of forgone healthcare, the highest proportion of forgone care was observed in Chittagong region (around 4\%) and lowest in Mymensingh (around 1\%) (Fig. 2C). With exception to Chittagong, pro-poor inequalities were observed in all other regions (Fig. 2D).

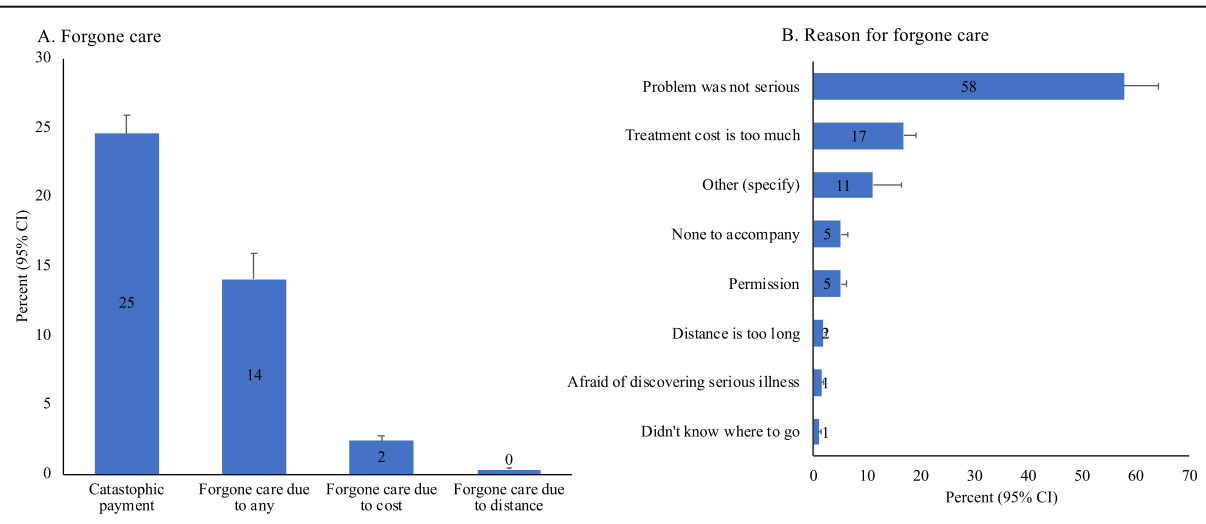

Fig. 1 Financial burden, forgone care, and reason for forgone care in Bangladesh, 2017 
Table 3 Multilevel Poisson regression model of risk of forgone healthcare, Bangladesh, $2017(N=39,124)$

\begin{tabular}{|c|c|c|c|c|}
\hline Variable & Frequency of forgone healthcare & Proportion $(95 \% \mathrm{Cl})$ & RR $(95 \% \mathrm{Cl})$ & $p$-values \\
\hline \multicolumn{5}{|l|}{ Age, years } \\
\hline $0-4$ & 47 & $1.0(0.6-1.5)$ & 1.00 & \\
\hline $5-9$ & 54 & $1.4(1.1-2.0)$ & $2.03(1.07-3.87)$ & 0.03 \\
\hline $10-14$ & 59 & $1.8(1.3-2.5)$ & $2.59(1.44-4.66)$ & $<0.01$ \\
\hline $15-19$ & 58 & $2.1(1.5-2.8)$ & $3.15(1.76-5.65)$ & $<0.01$ \\
\hline $20-24$ & 56 & $2.3(1.6-3.1)$ & $3.67(1.93-6.99)$ & $<0.01$ \\
\hline $25-64$ & 504 & $3.0(3.5-5.6)$ & $3.87(2.06-7.26)$ & $<0.01$ \\
\hline$\geq 65$ & 116 & $4.4(3.5-5.6)$ & $4.79(2.44-9.37)$ & $<0.01$ \\
\hline \multicolumn{5}{|l|}{ Gender } \\
\hline Female & 537 & $2.5(2.1-2.9)$ & 1.00 & \\
\hline Male & 537 & $2.2(1.8-2.6)$ & $0.79(0.65-0.96)$ & 0.02 \\
\hline \multicolumn{5}{|l|}{ Religion } \\
\hline Muslim & 802 & $2.4(2.0-2.8)$ & 1.00 & \\
\hline Non-Muslim & 92 & $2.2(1.5-3.2)$ & $0.91(0.70-1.19)$ & 0.50 \\
\hline \multicolumn{5}{|l|}{ Marital status } \\
\hline Never married & 178 & $1.7(1.4-2.2)$ & 1.00 & \\
\hline Currently married & 545 & $2.8(2.4-3.4)$ & $0.81(0.58-1.14)$ & 0.22 \\
\hline Widowed* & 113 & $4.7(3.6-6.0)$ & $1.11(0.74-1.66)$ & 0.61 \\
\hline \multicolumn{5}{|l|}{ Has a chronic disease } \\
\hline No & 397 & $1.5(1.2-1.7)$ & 1.00 & \\
\hline Yes & 498 & $4.5(2.8-5.4)$ & $1.73(1.45-2.07)$ & $<0.01$ \\
\hline \multicolumn{5}{|l|}{ Income earner } \\
\hline No & 587 & $2.4(2.0-2.8)$ & 1.00 & \\
\hline Yes & 278 & $2.9(2.4-3.5)$ & $1.09(0.90-1.32)$ & 0.37 \\
\hline \multicolumn{5}{|l|}{ Consumption quintile } \\
\hline Q1 (poorest) & 261 & $4.5(3.7-5.5)$ & 1.00 & \\
\hline Q2 & 146 & $2.4(1.8-3.1)$ & $0.47(0.37-0.60)$ & $<0.01$ \\
\hline Q3 & 138 & $1.6(1.3-2.1)$ & $0.36(0.28-0.46)$ & $<0.01$ \\
\hline Q4 & 148 & $1.8(1.4-2.5)$ & $0.25(0.20-0.33)$ & $<0.01$ \\
\hline Q5 (richest) & 202 & $2.2(1.5-3.2)$ & $0.18(0.14-0.24)$ & $<0.01$ \\
\hline Household size & - & - & $1.06(1.01-1.11)$ & 0.02 \\
\hline \multicolumn{5}{|l|}{ Place of residence } \\
\hline Rural & 680 & $2.6(2.2-3.0)$ & 1.00 & \\
\hline Urban & 215 & $1.7(1.2-2.5)$ & $0.98(0.76-1.27)$ & 0.90 \\
\hline Total & 895 & $2.4(2.0-2.7)$ & & \\
\hline
\end{tabular}

$R R$ relative risk, $\mathrm{Cl}$ confidence interval

*Widowed/Divorced/Separated

${ }^{\mathrm{a}} p<0.01 ;{ }^{\mathrm{b}} p<0.05 ;{ }^{\mathrm{c}} p>0.6$

\section{Discussion}

The main focus of this study was to assess the determinants of the level of OOP payments, the resulting financial risk and the probability of forgone healthcare in Bangladesh. This is the first attempt in Bangladesh to identify the potential factors which influence both financial burden and forgone healthcare using the most recent nationally representative household survey data.
The findings suggested that 1 in 4 Bangladeshis incurred financial catastrophe and $14 \%$ population had forgone healthcare for any reason. Individuals having chronic illness and having higher economic status are the common determinants of OOP payments, CHE and forgone healthcare. Inpatient and outpatient public and private health services were key predictors for OOP payments and $\mathrm{CHE}$. 

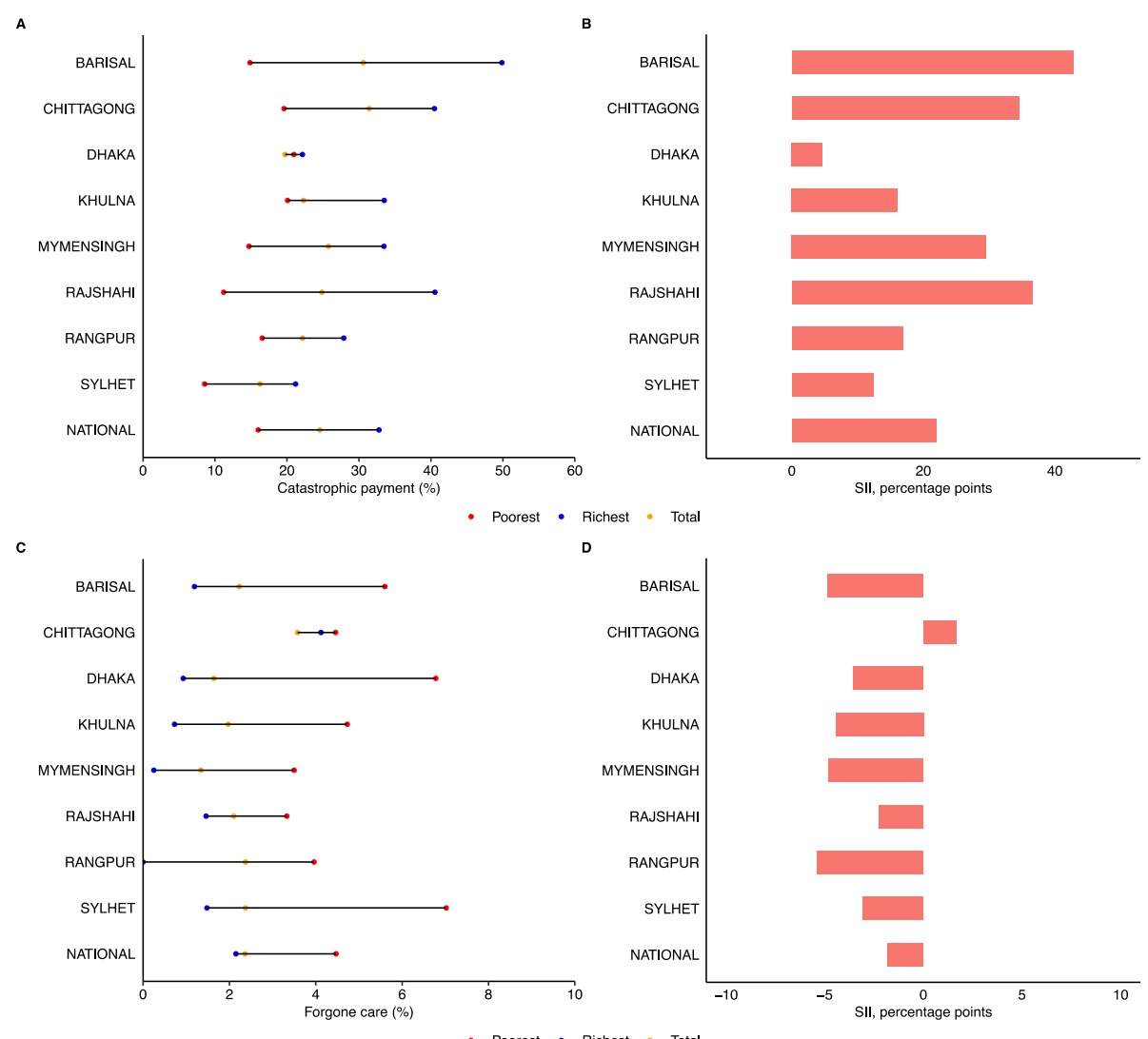

Fig. 2 Quintile-specific incidence of catastrophic health payments and forgone healthcare by region in Bangladesh, 2017. Note: A. Household consumption quintile-specific catastrophic health payments (top left); B. Slope index of inequality for catastrophic health payments (top right); D. Household consumption quintile-specific forgone healthcare (bottom left); B. Slope index of inequality for forgone healthcare (bottom right)

Our study indicated that more than 1 in 10 Bangladeshis reported foregone healthcare in the last 12 months. Among those who do not seek care, the main reasons for foregone healthcare were related to treatment cost, permission, none to accompany, and distance to health facilities. Our study indicated that around $25 \%$ of households in Bangladesh incurred financial catastrophe when they received health services. Wealthy household, household member with chronic disease, both public and private health service users faced increased risk of catastrophic health payments. These findings are consistent with a previous study conducted in Bangladesh $[13,14,25,34-36]$. Although the Bangladeshi public health facilities are highly subsidized, they fail to protect households against catastrophic health payments. In our study, household consumption quintile had a linear negative association with the forgoing of medical care for high treatment costs reasons, which is in consensus with results from previous studies [37]. Our study findings highlight that persons with lower income group in Bangladesh were at greater risk of forgoing treatment due to cost more frequently. Consistent with previous studies [38], elderly and people with chronic diseases were found to be more likely to forgo care. Given the sharply rising prevalence of chronic diseases in LMICs $[20,25,39,40]$, the expenditures for these conditions will add to the current burden of costs associated with infectious diseases, creating further challenges for households to obtain necessary care. Case in point, $17 \%$ of foregone care was attributed to affordability of medical fees or medications which raises concerns regarding the ability of Bangladesh health care system to cater for the low-income groups. This compared to only $3 \%$ of foregone care being associated with availability of health services such as distance further highlights the significance of direct healthcare payments as a barrier more than other dimensions of barriers in Bangladesh.

Being a developing country with majority rural residents, Bangladesh utilizes the concerted efforts of government, non-government, private and international organizations to deliver basic healthcare services for its population. However, despite such promising collaboration across the country, a high burden of OOP payment persists which demonstrates underlying myriad of contributing factors. To begin with, the poorly designed health financing system in Bangladesh continues to lack 
insurance policies which not only forces the general people to adopt distress financing for healthcare but also discourages them from seeking services when in need. The excessive financial burden often leads the families to modify their health service utilization pattern, and those who suffer from multiple chronic diseases consequently face worsening health conditions requiring vastly expensive treatments. Studies have shown that health insurance schemes not only successfully promote effective service utilization but also ensure simultaneous reduction in such relinquishment of care [41, 42]. The Government of Bangladesh has instead subsidized its public health facilities to a bare minimum cost of care, but unfortunately the hidden expenditures in forms of unofficial medical charges, financial incentives or tips to the porters and female helpers (ayas), and travel and food costs make institutional care an expensive experience for underserved populations [43]. Moreover, the frequent understaffing at the government health centers (due to absent healthcare providers at the sanctioned positions), hostile behavior of their available workforce, long waiting periods and inconvenient opening and closing times further restrain the poor people from using their services [44]. Concurrently, most impoverished health users suffer from indecisions, reduced perception of medical need, lack of awareness regarding the proper health center, financial uncertainty and perceived economic inadequacy - all of which cumulatively cause them to forgo essential healthcare and subsequently face devastating out-of-pocket expenditures.

This is the first study providing evidence of prevalence, inequalities and determinants of burden of OOP payments and foregone healthcare in the Bangladeshi population using recent large-scale nationwide survey data. Notwithstanding these strengths, is important to recognize the limitations of this study. First, the inability to estimate causal effects derives from the lack of control for reverse causality between predictors and occurrence of burden of OOP payments and forgone healthcare. Secondly, there may have been an issue of recall bias when respondents were asked if they limited medicines over a 12-month period.

\section{Conclusion and policy recommendations}

Around one in four Bangladeshi incur catastrophic health expenditure, $14 \%$ population forgone healthcare, and treatment is the leading reason for forgone healthcare in Bangladesh. This study demonstrated that individuals who are chronically ill, users of either public or private health services, and belonging to wealthy socioeconomic condition have increased risks for OOP payment and catastrophic health expenditure. Forgone healthcare is also influenced by individual's chronic illness, economic status, and place of residence.
Socioeconomically disadvantaged population are reported more likely to forgo health services for high treatment costs in Bangladesh.

In Bangladesh's current health financing system, the costs associated with chronic disease fall most severely upon those least able to afford them, increasing the risk of financial hardship and impoverishment for the families concerned. Advancement towards achieving national health goals will only be accelerated by:

- Ensuring affordability of health services, reducing geographical barriers, and improving acceptability, will be critical in reducing forgone healthcare.

- Increasing government spending on health, properly monitoring subsidized programs, and committing to health insurance for the whole population, for salaried workers in both public and private sectors, and voluntary memberships for dependents, farmers and self-employed persons, similarly to programs in Vietnam, and other developing countries

- Expanding benefits packages for poor and chronically ill people to include highly-subsidized or free hospital services.

Abbreviations

CEA: Census enumerations area; $\mathrm{CHE}$ : Catastrophic health expenditure; $\mathrm{Cl}$ : Confidence interval; HIES: Household Income and Expenditure Survey; LMICs: Low- and middle-income countries; OOP: Out-of-pocket payment; PSU: Primary sampling units; RR: Relative risk; SIl: Slope index of inequality

\section{Supplementary Information}

The online version contains supplementary material available at https://doi org/10.1186/s13561-021-00348-6.

Additional file 1: Supplemental appendix. Table S1. Incidence of catastrophic health expenditure by different definitions and thresholds, Bangladesh $(n=39,124)$. Table S2: Heckman regression results for the total amount of OOP health payments, Bangladesh $2017(N=39,124)$.

\section{Acknowledgements}

Not applicable.

\section{Authors' contributions}

Rahman MM designed and conceptualized the study. Islam MR compiled, prepared data for analysis. Rahman MM performed statistical analysis. Rahman MM contributed to interpretation of findings. Rahman MM and Hossain F wrote the first draft of the paper. Rahman MS, Rahman MO, and Islam MR check the consistency of results. Jung J, Akter S, and Alam A revised the manuscript revised the manuscript. All authors read and approved the final manuscript.

Funding

This research is supported Hitotsubashi University, Japan.

Availability of data and materials

The is not publicly available. The corresponding author is fully responsible for data gathering.

\section{Declarations}

Ethics approval and consent to participate Not applicable. 


\section{Consent for publication}

Not applicable.

\section{Competing interests}

We declare no competing interests.

\section{Author details}

${ }^{1}$ Hitotsubashi Institute for Advanced Study, Hitotsubashi University, 2-1 Naka Kunitachi, Tokyo 186-8601, Japan. ${ }^{2}$ Department of Global Health Policy, School of International Health, The University of Tokyo, Tokyo, Japan. ${ }^{3}$ Research Centre for Child Mental Development, Hamamatsu University School of Medicine, Hamamatsu, Japan. ${ }^{4}$ Global Public Health Research Foundation, Dhaka, Bangladesh. ${ }^{5}$ Department of Global Health Nursing, Graduate School of Nursing Science, St. Luke's International University, Tokyo, Japan.

Received: 19 July 2021 Accepted: 8 December 2021 Published online: 10 January 2022

\section{References}

1. United Nations. Transforming our world: the 2030 agenda for sustainable development. New York: Division for Sustainable Development Goals; 2015.

2. DeMaris A. Combating unmeasured confounding in cross-sectional studies: evaluating instrumental-variable and Heckman selection models. Psychol Methods. 2014:19(3):380-97. https://doi.org/10.1037/a0037416.

3. Wagstaff A, Flores G, Hsu J, Smitz MF, Chepynoga K, Buisman LR, et al. Progress on catastrophic health spending in 133 countries: a retrospective observational study. Lancet Glob Health. 2018;6(2):e169-e79. https://doi. org/10.1016/S2214-109X(17)30429-1.

4. Wagstaff A, Flores G, Smitz M-F, Hsu J, Chepynoga K, Eozenou P. Progress on impoverishing health spending in 122 countries: a retrospective observational study. The Lancet Global Health. 2018;6(2):e180-e192. https:// doi.org/10.1016/S2214-109X(17)30486-2.

5. Jacobs $B$, Ir P, Bigdeli M, Annear PL, Van Damme W. Addressing access barriers to health services: an analytical framework for selecting appropriate interventions in low-income Asian countries. Health Policy Plan. 2012;27(4): 288-300. https://doi.org/10.1093/heapol/czr038.

6. Su TT, Kouyate B, Flessa S. Catastrophic household expenditure for health care in a low-income society: a study from Nouna District. Burkina Faso Bull World Health Organ. 2006;84(1):21-7.

7. Andersen RM. Revisiting the behavioral model and access to medical care: does it matter. J Health Soc Behav. 1995;36(1):1-10. https://doi.org/10.23 $07 / 2137284$

8. Tanahashi T. Health service coverage and its evaluation. Bull World Health Organ. 1978;56(2):295-303.

9. Levesque JF, Harris MF, Russell G. Patient-centred access to health care: conceptualising access at the interface of health systems and populations. Int J Equity Health. 2013;12(1):18. https://doi.org/10.1186/1475-9276-12-18.

10. Peters DH, Garg A, Bloom G, Walker DG, Brieger WR, Rahman MH. Poverty and access to health care in developing countries. Ann N Y Acad Sci. 2008; 1136(1):161-71. https://doi.org/10.1196/annals.1425.011.

11. World Health Organization. Bangladesh health system review: Manila: WHO Regional Office for the Western Pacific; 2015.

12. Health Economics Unit. Bangladesh National Health Accounts, an overview on the public and private expenditures in health sector [Internet]. Available from: https://www.who.int/bangladesh/news/detail/05-10-2017-bangladeshnational-health-accounts-an-overview-on-the-public-and-privateexpenditures-in-health-sector [cited 2020 Dec 26].

13. Islam MR, Rahman MS, Islam Z, Sultana P, Rahman MM. Inequalities in financial risk protection in Bangladesh: an assessment of universal health coverage. Int J Equity Health. 2017;16(1):59. https://doi.org/10.1186/s12939017-0556-4.

14. Rahman MS, Rahman MM, Gilmour S, Swe KT, Abe SK, Shibuya K. Trends in, and projections of, indicators of universal health coverage in Bangladesh, 1995-2030: a Bayesian analysis of population-based household data. Lancet Glob Health. 2018;6(1):e84-94. https://doi.org/10.1016/S2214-109X(17)30413-8.

15. Brinda EM, Rajkumar AP, Enemark U, Prince M, Jacob KS. Nature and determinants of out-of-pocket health expenditure among older people in a rural Indian community. Int Psychogeriatr. 2012;24(10):1664-73. https://doi. org/10.1017/S104161021200083X.
16. Wagstaff A, van Doorslaer E. Catastrophe and impoverishment in paying for health care: with applications to Vietnam 1993-1998. Health Econ. 2003; 12(11):921-34. https://doi.org/10.1002/hec.776.

17. Barros AJ, Bertoldi AD. Out-of-pocket health expenditure in a population covered by the family health program in Brazil. Int J Epidemiol. 2008;37(4): 758-65. https://doi.org/10.1093/ije/dyn063.

18. van Doorslaer E, O'Donnell O, Rannan-Eliya RP, Somanathan A, Adhikari SR, Garg CC, et al. Catastrophic payments for health care in Asia. Health Econ. 2007;16(11):1159-84. https://doi.org/10.1002/hec.1209.

19. Russell S. Ability to pay for health care: concepts and evidence. Health Policy Plan. 1996;11(3):219-37. https://doi.org/10.1093/heapol/11.3.219.

20. Bonfrer I, Gustafsson-Wright E. Health shocks, coping strategies and foregone healthcare among agricultural households in Kenya. Glob Public Health. 2017;12(11):1369-90. https://doi.org/10.1080/17441692.2015.1130847.

21. Calzón Fernández S, Fernández Ajuria A, Martín JJ, Murphy MJ. The impact of the economic crisis on unmet dental care needs in Spain. J Epidemiol Community Health. 2015;69(9):880-5. https://doi.org/10.1136/jech-2014-204493.

22. Cavalieri M. Geographical variation of unmet medical needs in Italy: a multivariate logistic regression analysis. Int J Health Geogr. 2013;12(1):27. https://doi.org/10.1186/1476-072X-12-27.

23. Van Minh H, Kim Phuong NT, Saksena P, James CD, Xu K. Financial burden of household out-of pocket health expenditure in Viet Nam: findings from the National Living Standard Survey 2002-2010. Soc Sci Med. 2013;96:25863. https://doi.org/10.1016/j.socscimed.2012.11.028.

24. Chuma J, Maina T. Catastrophic health care spending and impoverishment in Kenya. BMC Health Serv Res. 2012;12(1):413. https://doi.org/10.1186/14726963-12-413.

25. Rahman MM, Gilmour S, Saito E, Sultana P, Shibuya K. Health-related financial catastrophe, inequality and chronic illness in Bangladesh. PLoS One. 2013;8(2):e56873. https://doi.org/10.1371/journal.pone.0056873.

26. Bremer $P$. Forgone care and financial burden due to out-of-pocket payments within the German health care system. Health Econ Rev. 2014; 4(1):36. https://doi.org/10.1186/s13561-014-0036-0.

27. Li X, Chen M, Wang Z, Si L. Forgone care among middle aged and elderly with chronic diseases in China: evidence from the China health and retirement longitudinal study baseline survey. BMJ Open. 2018:8(3):e019901. https://doi.org/10.1136/bmjopen-2017-019901.

28. Li Y, Wu Q, Xu L, Legge D, Hao Y, Gao L, et al. Factors affecting catastrophic health expenditure and impoverishment from medical expenses in China: policy implications of universal health insurance. Bull World Health Organ. 2012;90(9):664-71. https://doi.org/10.2471/BLT.12.102178.

29. Gotsadze G, Zoidze A, Rukhadze N. Household catastrophic health expenditure: evidence from Georgia and its policy implications. BMC Health Serv Res. 2009;9(1):69. https://doi.org/10.1186/1472-6963-9-69.

30. Brinda EM, Andres AR, Enemark U. Correlates of out-of-pocket and catastrophic health expenditures in Tanzania: results from a national household survey. BMC Int Health Hum Rights. 2014;14(1):5. https://doi. org/10.1186/1472-698X-14-5.

31. Heckman JJ. Sample selection bias as a specification error. Econometrica. 1979:47(1):153-61. https://doi.org/10.2307/1912352.

32. Barros AJHV. Alternatives for logistic regression in cross-sectional studies: an empirical comparison of models that directly estimate the prevalence ratio. BMC Med Res Methodol. 2003;20(3):21. https://doi.org/10.1186/1471-2288-3-21.

33. G. Z. A modified poisson regression approach to prospective studies with binary data. Am J Epidemiol 2004; 159(7): 702-706, https://doi.org/10.1093/aje/kwh090.

34. Khan JA, Ahmed S, Evans TG. Catastrophic healthcare expenditure and poverty related to out-of-pocket payments for healthcare in Bangladesh-an estimation of financial risk protection of universal health coverage. Health Policy Plan. 2017;32(8):1102-10. https://doi.org/10.1093/heapol/czx048.

35. Rahman MM, Gilmour S, Saito E, Sultana P, Shibuya K. Self-reported illness and household strategies for coping with health-care payments in Bangladesh. Bull World Health Organ. 2013;91(6):449-58. https://doi.org/1 0.2471/BLT.12.115428.

36. Rahman MM, Karan A, Rahman MS, Parsons A, Abe SK, Bilano V, et al. Progress toward universal health coverage: a comparative analysis in 5 south Asian countries. JAMA Intern Med. 2017;177(9):1297-305. https://doi. org/10.1001/jamainternmed.2017.3133.

37. Guessous I, Theler J-M, Izart CD, Stringhini S, Bodenmann P, Gaspoz JM, et al. Forgoing dental care for economic reasons in Switzerland: a six-year cross-sectional population-based study. BMC Oral Health. 2014;14(1):121. https://doi.org/10.1186/1472-6831-14-121. 
38. Nikoloski Z, Ajwad Ml. Do economic crises lead to health and nutrition behavior responses? Analysis using longitudinal data from Russia: the World Bank; 2013. https://doi.org/10.1596/1813-9450-6538.

39. Aikins A-G, Unwin N, Agyemang C, Allotey P, Campbell C, Arhinful D.

Tackling Africa's chronic disease burden: from the local to the global. Glob Health. 2010;6(1):1-7.

40. Rahman MM, Akter S, Jung J, Rahman MS, Sultana P. Trend, projection, and appropriate body mass index cut-off point for diabetes and hypertension in Bangladesh. Diabetes Res Clin Pract. 2017;126:43-53. https://doi.org/10.101 6/j.diabres.2017.01.008.

41. Gross DJ, Alecxih L, Gibson MJ, Corea J, Caplan C, Brangan N. Out-of-pocket health spending by poor and near-poor elderly medicare beneficiaries. Health Serv Res. 1999:34(1 Pt 2):241-54.

42. Xu X, Patel DA, Vahratian A, Ransom SB. Insurance coverage and health care use among near-elderly women. Womens Health Issues. 2006;16(3):139-48. https://doi.org/10.1016/j.whi.2006.02.005.

43. Nahar S, Costello A. The hidden cost of 'free'maternity care in Dhaka. Bangladesh Health Policy Plan. 1998;13(4):417-22. https:/doi.org/10.1093/ heapol/13.4.417.

44. Banik BK. Barriers to access in maternal healthcare services in the northern Bangladesh. South East Asia J Public Health. 2016;6(2):23-36. https://doi. org/10.3329/seajph.v6i2.31832.

\section{Publisher's Note}

Springer Nature remains neutral with regard to jurisdictional claims in published maps and institutional affiliations.

Ready to submit your research? Choose BMC and benefit from:

- fast, convenient online submission

- thorough peer review by experienced researchers in your field

- rapid publication on acceptance

- support for research data, including large and complex data types

- gold Open Access which fosters wider collaboration and increased citations

- maximum visibility for your research: over $100 \mathrm{M}$ website views per year

At BMC, research is always in progress.

Learn more biomedcentral.com/submissions 